\title{
Percepção de Jovens Brasileiros sobre as Repercussões das Redes Sociais na Subjetividade
}

\author{
Gabriel Artur Marra e Rosa ${ }^{1}$ (D), Jane Farias Chagas Ferreira ${ }^{2, *}$ (D), Ana Gabriela Mauch ${ }^{2}$ (D),

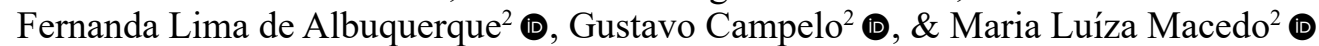 \\ ${ }^{1}$ Universidad del Salvador, Buenos Aires, Argentina \\ ${ }^{2}$ Universidade de Brasília, Brasilia, DF, Brasil
}

\begin{abstract}
RESUMO-O presente estudo teve como objetivo analisar a percepção de jovens brasileiros acerca de possíveis repercussões das redes sociais na subjetividade dos usuários. Participaram da pesquisa 50 jovens, de ambos os sexos, faixa etária de 18 a 26 anos de idade, em sua maioria com escolaridade de nível superior incompleto e todos residentes no Distrito Federal. Com base na metodologia qualitativa, foram realizadas entrevistas semiestruturadas e os dados obtidos foram analisados por meio da técnica da Zona de Sentidos. Os resultados evidenciam que as redes sociais exercem influência determinante na concepção de mundo e de si mesmo dos participantes por meio de recursos atrativos que geram gratificações, capturam a atenção e promovem a utilização constante das redes.
\end{abstract}

PALAVRAS-CHAVE: redes sociais, percepção, jovens, repercussões, subjetividade

\section{Perception of Young Brazilians Regarding the Effects of Social Networks on Subjectivity}

\begin{abstract}
This study has the objective of analyzing the perception of young Brazilians about the possible repercussions of social networks on users' subjectivity. A total of 50 young adults of both genders, ranging from ages 18 to 26 , the majority undergraduate students, all residents in the Federal District participated in the study. Based on the qualitative methodology, semi-structured interviews were performed and the data was analyzed through the Zones of Sense (Zonas de Sentido) technique. The results evidence that social networks have a determined influence in the user's conception of the world and self through interesting resources that generate rewards, catch the attention and promote the constant use of these networks.
\end{abstract}

KEYWORDS: social networks, perception, young adults, impacts, subjectivity

Os efeitos imediatos das redes sociais são evidentes nos mais diversos setores da sociedade. A princípio, houve certa desconfiança em relação ao potencial transformador de ferramentas que funcionam por meio de dispositivos conectados à Internet e, por conseguinte, ao intangível ciberespaço. Não obstante o receio inicial, a comunidade científica internacional rapidamente reconheceu a magnitude desse fenômeno global e suas possíveis repercussões nos marcos coletivos da sensibilidade humana (Lévy, 1996; Stokols, 2018).

Em pouco mais de duas décadas desde o advento da internet, viu-se o número de usuários crescer de forma exorbitante. Em 2016, de acordo com dados divulgados pelo IBGE relativos à Pesquisa Nacional por Amostra de Domicílios Contínua - PNAD, cerca de $65 \%$ da população brasileira (estimada em 209 milhões de pessoas) com mais de 10 anos de idade teve acesso à internet, sendo que $95 \%$ dos usuários o fizeram pelo celular para enviar mensagens de texto, voz, vídeo e imagens. Esse número cresceu deliberadamente entre jovens com idade entre 18 e 24 anos (IBGE/PNAD, 2018).

Neste amplo espectro da internet, as mídias sociais, mais conhecidas como redes sociais, incluem blogs, sites de compartilhamento de fotos e vídeos, bem como plataformas que permitem aos usuários a criação e o compartilhamento de conteúdo (Boyd, 2014). Entre elas, o Facebook é

\footnotetext{
*E-mail: janefc@unb.br

- Submetido: 26/11/2018; Aceito: 07/09/2020.
} 
atualmente a rede social mais utilizada, tendo contabilizado a média mundial de mais de 3 bilhões de usuários (Facebook, 2020). De acordo com a página oficial do Facebook, o Brasil é o quarto país do mundo em número de perfis ativos, com aproximadamente 120 milhões de usuários/mês.

As pesquisas sobre redes sociais revelam certa contradição em relação ao bem-estar das pessoas que as acessam cotidianamente, sendo essa relação frequentemente analisada a partir do tipo de uso efetuado e o incremento ou a diminuição da autoestima dos participantes (Best, Manktelow \& Taylor, 2014; Andreassen, Pallesen \& Griffiths, 2017). Do mesmo modo, o estado de humor, a autoimagem e a imagem corporal tendem a ser variáveis analisadas a partir das modalidades de autoapresentação (self-presentation) (Ferrari \& Moraes, 2017). Essas modalidades incluem descrições, postagens e gerenciamento de fotos, além do tipo de interação entre os participantes (Fardoulya et al., 2015; Chua \& Chang, 2016).

Por outro lado, investigações recentes demonstram que, por meio da expressão de pensamentos, sentimentos e desejos (self-expression), as contradições dos seres humanos estão cada vez mais expostas e isso pode ocasionar níveis diferenciados de produção subjetiva e elaboração psíquica (Rosa, Santos \& Chagas-Ferreira, 2016; Rosa, Santos, Stengel \& Freitas, 2016).

Neste contexto imbricado e inovador, jovens e adolescentes são o estrato da sociedade mais observado pelos estudiosos das redes sociais em virtude de se encontrarem em uma etapa de transição no desenvolvimento psicossocial. Os adolescentes passam por transformações significativas não somente no corpo físico, que transita entre a infância e a vida adulta, mas também na sexualidade e na construção de suas identidades (Erikson, 1980). Os jovens, por sua vez, transitam pela fase de consolidação dos vínculos afetivos e dos projetos vitais nos âmbitos vocacional e laboral.

As pesquisas evidenciam que as principais motivações que levam os jovens a utilizar as redes sociais são de ordem relacional e emocional (Colás, González \& De Pablos, 2013). A primeira refere-se ao fato de poder manter contato com amigos e a segunda, por sua vez, ao reconhecimento pessoal e reforço da autoestima. Igualmente, a possibilidade de se expor e de demonstrar seus interesses, inclusive sexuais, também constam como motivações para que eles utilizem as redes sociais (Owan, Ekpe \& Eneje, 2020). Por último e não menos importante, a suposta proteção oferecida pelo ambiente virtual e o fato de poder conectarse independentemente das fronteiras de tempo e espaço são considerados também motivações relevantes para se tornar usuário das redes sociais (Reich, Subrahmanyam \& Espinoza, 2012; Stokols, 2018).

Diante do exposto, o presente trabalho teve como objetivo analisar a percepção de jovens brasileiros acerca das possíveis repercussões das redes sociais na subjetividade dos usuários. Para tanto, a construção do método foi baseada na utilização de dois conceitos-chave: percepção e sentido subjetivo. O primeiro descreve o processo de tornar-se consciente, o qual envolve atividades como reconhecer, observar e discriminar (APA, 2010). O conceito de sentido subjetivo, por seu turno, vai além dos sentidos pelos quais o sujeito percebe informações do ambiente externo ou do seu corpo em relação ao ambiente.

Segundo González-Rey (2010), o sentido subjetivo abrange registros diferenciados da experiência vivida que são específicos dos processos psíquicos dos seres humanos imersos no ambiente cultural. Esses registros compõem uma organização subjetiva complexa, que reúne emoções, significados e processos simbólicos suscetíveis de serem percebidos por outro ser humano em um determinado momento. O sentido subjetivo é, portanto, elemento fundador e produto da subjetividade na medida em que ela se organiza de maneira dinâmica em práticas de indivíduos e grupos que constituem a sociedade.

A partir da articulação entre os conceitos de percepção e sentido subjetivo, a análise da percepção dos jovens sobre as redes sociais foi realizada à luz da epistemologia qualitativa e da técnica da zona de sentidos, que considera o caráter construtivo da pesquisa qualitativa fundamental e enfatiza o momento empírico como um processo de interpretação e ressignificação do pesquisador sobre as diversas formas de expressão do sujeito (González-Rey, 1997; 2010).

\section{MÉTODO}

\section{Participantes}

Participaram do estudo 50 jovens usuários de redes sociais, com idade média de 21,4 anos (DP $=1,88$ ), variando entre 18 e 26 anos de idade. Destes, 68\% eram do sexo feminino $(n=34)$ e $32 \%$ do sexo masculino $(n=$ 16). Quanto ao nível de escolaridade, $4 \%$ tinham o ensino médio completo, $84 \%$ o curso superior incompleto e $12 \%$ haviam completado o nível superior. Todos os participantes residiam no Distrito Federal.

\section{Instrumentos}

Para a coleta de dados, foi utilizado um roteiro de entrevista semiestruturada (Flick, 2014) e um questionário. O questionário visou obter informações acerca das características sociodemográficas como sexo, idade, nível de escolaridade, redes sociais mais utilizadas e tempo dedicado a elas.

$O$ roteiro de entrevista foi elaborado com o intuito de que os entrevistadores pudessem aludir aos sentidos subjetivos, atribuídos pelos jovens aos possíveis efeitos das redes sociais 
na subjetividade dos usuários. Essas perguntas visavam acessar as percepções relacionadas às experiências pessoais e aos sentidos subjetivos por meio do diálogo entre pesquisador e pesquisado, tal como enfatiza a epistemologia qualitativa adotada no estudo. São exemplos de perguntas: "Como foi seu primeiro contato com as redes sociais?"; "E o que atraiu você?"; "Você considera que a maneira como se mostra nas redes sociais reflete a realidade?"; e "Você considera que as pessoas são iguais nas redes sociais e fora delas?”.

\section{Procedimentos}

Os participantes foram convidados a aderirem à pesquisa e puderam indicar outros voluntários para a coleta de dados por meio do procedimento denominado "Bola de Neve" (Biernacki \& Waldorf, 1981; Rosa, Santos \& Chagas, 2016). Assumindo os pressupostos teóricos-metodológicos da investigação qualitativa (Creswell, 2014), o trabalho teve como imperativo analisar as interações com as redes sociais por meio da percepção dos sujeitos (Rosa, Santos \& Chagas, 2016). Nesta direção, utilizou-se instrumental técnico-teórico oriundo da metodologia qualitativa com base na abordagem interacionista simbólica, que tem como premissas: (a) os seres humanos atuam na relação com os objetos com base nos significados que eles mesmos tecem sobre estes; (b) o significado dos objetos se origina da interação social; (d) os significados são controlados por um processo interpretativo e são modificados por meio deste mesmo processo (Carvalho, Borges \& Rêgo, 2010).

Depois de terem recebido informações sobre os objetivos da pesquisa e terem assinado o Termo de Consentimento
Livre e Esclarecido, foi aplicado o questionário e realizada a entrevista em ambiente privado, levando-se em consideração a conveniência dos entrevistados. Os dados foram gravados com o auxílio de smartphones e transcritos na íntegra para análise posterior.

\section{Análise dos Dados}

Os dados obtidos nas entrevistas foram analisados por meio da técnica da Zona de Sentidos, conforme elaborado por González-Rey (2005). Esta técnica propõe que, por meio dos relatos dos participantes, é possível compreender os significados e processos simbólicos que fazem emergir sentidos subjetivos procedentes da subjetividade individual e social. Vale ressaltar que estes sentidos subjetivos são inferidos tanto por meio da relação dos significados, emoções e processos simbólicos atribuídos pelos participantes a um determinado fenômeno social quanto pela subjetividade do próprio pesquisador, que é capaz de percebê-los e colocá-los em evidência. Portanto, o processo de sistematização das zonas de sentido não se dá por frequência de conteúdos nem tampouco por categorias pré-estabelecidas, mas sim pela interpretação e ressignificação do pesquisador sobre as diversas formas de expressão do sujeito.

Com o intuito de preservar a identidade dos participantes, os nomes utilizados para representar os entrevistados são fictícios. As respostas apresentadas nos resultados foram selecionadas devido a sua representatividade em relação às zonas de sentido construídas ao longo do processo de análise e interpretação dos dados.

\section{RESULTADOS}

Os dados obtidos com base no questionário sociodemográfico demonstraram que as redes sociais mais utilizadas pelos participantes são as seguintes: Facebook (94\%), Instagram (70\%), WhatsApp (60\%), Twitter (14\%) e Snapchat (12\%). Entre as menos citadas, apareceram o Pinterest (6\%), o Tumblr (6\%) e algumas redes sociais brasileiras que reúnem grupos com interesses específicos ou restritos, como Strava - rede social de ciclistas $(2 \%)$, Filmow - rede social de cinéfilos $(2 \%)$ e Skoob - rede social de leitores $(2 \%)$. Também foram indicados pelos jovens outros sites, plataformas e aplicativos como e-mails ou Messenger $(10 \%)$, Youtube $(6 \%)$ e outros ainda menos frequentes como Spotify, Tinder, Telegram, TV ShowTime e CouchSurfing.

Com relação ao tempo despendido nas redes sociais, ficou evidenciado que $70 \%$ dos jovens se conectava por mais de duas horas diárias nesses ambientes $(\mathrm{n}=35)$, sendo $48 \%$ por mais de 3 horas e $22 \%$ entre 2 e 3 horas. Apenas dois participantes informaram que acessam as redes sociais por até 30 minutos (4\%), 12\% ficavam conectados entre 30 minutos e 1 hora $(n=6)$ e os demais $14 \%$ entre 1 e 2 horas $(\mathrm{n}=7)$.

Ainda com relação às redes sociais, vale salientar que, durante as entrevistas, os jovens mencionaram aspectos positivos e negativos em relação ao ato de estar conectado. Entre os aspectos positivos, foram destacados a obtenção de informação $(f=34)$, interagir ou manter contato ( $f=$ $25)$ e a comunicação mais ágil e prática $(f=22)$. Entre esses aspectos estavam armazenar conteúdos, localizar pessoas e compartilhar arquivos. Os aspectos negativos majoritariamente mencionados foram agressividade e intolerância (24\%), exposição da própria vida (18\%), informações superficiais (16\%) e a aparência de vida perfeita ou atmosfera de falsa felicidade (10\%). Maiores detalhes sobre cada uma dessas nuances podem ser visualizados nas Tabelas 1 e 2, apresentadas a seguir. 
Tabela 1

Aspectos positivos relacionados à participação nas redes sociais $(N=50)$.

\begin{tabular}{lll}
\hline Aspectos positivos & F & \% \\
\hline Obtenção de informação: praticidade, facilidade e diversidade & 34 & 68 \\
Interagir ou manter contato & 25 & 50 \\
Agilidade na comunicação & 22 & 44 \\
Entretenimento & 7 & 14 \\
Saber da vida das pessoas conhecidas ou não & 7 & 14 \\
Disponibilidade das mídias (fotos e vídeos) & 5 & 10 \\
Saber sobre eventos & 4 & 8 \\
Passar o tempo & 3 & 6 \\
Compartilhar momentos & 3 & 6 \\
Interação virtual sem contato pessoal & 3 & 6 \\
Liberdade de expressão & 1 & 2 \\
Encontrar velhos conhecidos & 1 & 2 \\
Armazenar conteúdos & 1 & 2 \\
Compartilhar arquivos & 1 & 2 \\
Ver reação das pessoas & 1 & 2 \\
Localizar pessoas & 1 & \\
\hline
\end{tabular}

Tabela 2

Aspectos negativos relacionados à participação nas redes sociais $(N=50)$

\begin{tabular}{|c|c|c|}
\hline Aspectos Negativos & f & $\%$ \\
\hline Agressividade e intolerância & 12 & 24 \\
\hline Exposição da própria vida & 9 & 18 \\
\hline Informações superficiais & 8 & 16 \\
\hline Aparência de vida perfeita ou atmosfera de falsa felicidade & 5 & 10 \\
\hline Dependência & 4 & 8 \\
\hline Invasão de privacidade & 3 & 6 \\
\hline Discussões & 3 & 6 \\
\hline Imediatismo para dar respostas & 3 & 6 \\
\hline Tempo demandado & 3 & 6 \\
\hline Pouco contato com as pessoas & 3 & 6 \\
\hline Necessidade de likes ou aprovação & 3 & 6 \\
\hline Contato com pessoas indesejáveis ou com que não se tem intimidade & 2 & 4 \\
\hline Falta de ética ou bom senso & 3 & 6 \\
\hline Anúncios & 2 & 4 \\
\hline Insegurança & 2 & 4 \\
\hline Sentimento de competição & 1 & 2 \\
\hline Sensação de impunidade & 1 & 2 \\
\hline Distrações & 1 & 2 \\
\hline Cansativa & 1 & 2 \\
\hline Influência negativa & 1 & 2 \\
\hline Excesso de informação & 1 & 2 \\
\hline Correntes & 1 & 2 \\
\hline Animais violentados & 1 & 2 \\
\hline
\end{tabular}




\section{Zonas de Sentido}

A partir do conteúdo das entrevistas, foram elaboradas quatro zonas de sentido que condensam os sentidos subjetivos sobre as possíveis repercussões das redes sociais na subjetividade dos jovens usuários. Essas zonas foram nomeadas e definidas como: (1) "Capturados pela Rede" descreve a influência do meio social na opção por utilizar as redes e o efeito subsequente de não poder deixá-las; (2) "Rede Caça-Níqueis" - explicita o sentido de gratificação e de encontrar "coisas interessantes" que fomentam a dedicação de tempo excessivo ao uso das redes sociais; (3) "Termômetro de Si" - discorre sobre o efeito das interações nas redes na autoestima e no autoconceito dos participantes; e (4) "Espelho da Sociedade" - sintetiza as repercussões da participação em discussões provenientes da sociedade na concepção de mundo e na tensão entre os âmbitos público e privado. Não foram evidenciadas diferenças significativas na percepção dos participantes em relação às variáveis sexo e idade.

(1) Capturados pela rede. A percepção de haverem sido capturados pelas redes sociais surgiu como algo naturalizado entre os participantes. Ao serem questionados sobre o motivo de aderiram às redes, os jovens alegaram que, ao mesmo tempo em que desejavam inserir-se neste ambiente virtual, também viam o acesso aos serviços oferecidos pelas redes como algo necessário para o convívio na atualidade. De fato, $50 \%$ dos participantes da pesquisa consideravam que as redes sociais eram um meio para interagir e manter contato, enquanto $44 \%$ as consideravam como uma ferramenta que agiliza a comunicação. Esses dados demonstram que o interesse em interagir e comunicar-se com os demais pode estar também vinculado ao desejo de inserção no meio social ao qual eles pertencem. Segundo os entrevistados, essa influência provém de seus pares, os quais utilizam as redes frequentemente para relacionarem-se, tal como descreveu Maria: "Porque 'tava' todo mundo, né? Naquela 'vibe' de ter rede social. Então meio que isso influenciou e eu acabei entrando nisso também".

Essa influência notória descrita pela jovem tem sido associada por pesquisadores ao fenômeno da psicologia de grupos chamado efeito manada (Rosa \& Santos, 2013), cuja característica principal é a experiência de seguir uma tendência massiva de comportamento e de formas de pensar, que geralmente são provenientes de um grupo majoritário. No entanto, o sentido de haver sido capturado por um processo maior, atribuído por eles ao fenômeno social em questão, vai além e demonstra que eles efetuaram um processo gradativo de aprendizagem, a partir do qual passaram de seguidores menos assíduos a usuários ativos dessas ferramentas. Na opinião dos entrevistados, o processo inclui aprender a realizar postagens e entender as regras e os códigos de convivência do ambiente virtual das redes. Um exemplo nítido da concepção geral de que há um processo de aprendizagem pode ser evidenciado no seguinte relato de Manuela: "Muitos acabam entrando nas redes sociais por influência e tentam seguir as mesmas linhas de forma de agir".

O relato de Manuela põe em evidência a percepção compartilhada pelos jovens de que essa influência inicial é capaz de capturá-los e moldar, de alguma maneira, a sua forma de agir. Em outras palavras, o que a participante descreve de forma singela contempla um sentido mais amplo de estar enlaçado ou envolvido por um fenômeno social que repercute diretamente na conduta das pessoas. Esse sentido de captura tende a permanecer após a influência inicial e a condicionar, de certo modo, o desenrolar da relação que os usuários estabelecem com a ferramenta e entre eles.

Esta proposição corrobora-se por meio da afirmação de Maria, na qual ela justifica a mudança de comportamento devido ao acesso a uma gama de informações: "[...] é uma coisa 'que a gente vicia', porque é muita informação, mas, muita informação... muita coisa nova chegando [...]". Assim como neste relato em destaque, na maioria das entrevistas foi possível verificar o uso das palavras vício, desperdício, excesso, entre outras que denotam o uso descomedido e coincidem com o sentido de haver sido captado ou capturado por uma rede atrativa e, ao mesmo tempo, aprisionadora.

A percepção generalizada de captura também surgiu nas entrevistas como motivo de preocupação e monitoramento por parte dos pais. Neste ponto, é importante advertir que diversos pesquisadores já haviam alertado acerca dos riscos do uso compulsivo das redes sociais e da inversão do tempo produtivo e de socialização (Andreassen, Pallesen \& Griffiths, 2017; Rosa, Santos \& Chagas-Ferreira, 2016). Por isso, é importante ressaltar o fato de que os jovens entrevistados reconhecem que o uso das redes sociais repercute no comportamento e, por conseguinte, na subjetividade dos usuários, gerando um sentido compartilhado de não conseguir escapar da rede.

(2) Rede Caça-Níqueis. A zona de sentido denominada Rede Caça-Níqueis originou-se de uma analogia realizada por um dos entrevistados sobre possíveis semelhanças entre as redes sociais e a máquina de caça-níqueis. $\mathrm{O}$ trecho a seguir extraído da entrevista de Paulo demonstra a origem da nomenclatura utilizada para descrever essa zona de sentido e suas principais características:

\section{É aquela sensação de... caça-níqueis, você pega o celular como se fosse girar um caça-níqueis e ver um prêmio. Você pega o celular e você quer ver alguma coisa interessante. A maioria das vezes, não tem nada, tem só as horas aqui.}

De acordo com Paulo, ele pega o celular como se fosse "girar um caça-níqueis" para descobrir se há algo que possa despertar o seu interesse (algo interessante) ou que possa agradá-lo (um prêmio). Ao aludir indiretamente ao acesso às redes sociais por intermédio do celular, ele diz que na maioria das vezes "não tem nada" e apenas encontra as horas, referindo-se ao cotidiano habitual e sem maiores 
novidades. Porém, o aspecto mais relevante do relato é o de que o celular é utilizado como um objeto por meio do qual se acessa a um ambiente específico - as redes sociais - onde é possível obter gratificação (prêmio) e conteúdo relevante (alguma coisa interessante).

Considerando a elevada quantidade de tempo que os participantes disseram dedicar ao uso das redes (48\% mais de 3 horas e $22 \%$ entre 2 e 3 horas por dia), é possível vislumbrar a existência de uma atividade cotidiana reiterativa na vida desses jovens, que é totalmente diferente de algo esporádico ou ocasional. De tal modo, postar fotos, comentários ou simplesmente observar o que está ocorrendo nesse ambiente tornou-se um hábito que demanda tempo. À vista disso, a analogia com a máquina caça-níquel advém do que Paulo denominou "prêmio" e também com os principais aspectos positivos listados pelos entrevistados, como: obtenção de informação, praticidade, facilidade e diversidade; interagir ou manter contato; agilidade na comunicação; e entretenimento.

Seguindo a linha de raciocínio, pode-se afirmar que a expectativa dos usuários de obtenção de gratificações por meio das redes é uma contingência que fomenta um tipo de conduta peculiar: revisar constantemente o que está ocorrendo neste ambiente virtual. Por outro lado, a consequência dessa rotina de uso frequente é percebida por parte dos jovens entrevistados não somente como benéfica, mas também como causadora de ansiedade e mal-estar (Bento, 2016). De fato, parte dos jovens entrevistados mencionou como aspectos negativos tanto o uso desmedido como o excesso de tempo dedicado às redes (dependência $=8 \%$; tempo demandado $=6 \%$ ).

Decerto, não somente o excesso de uso, mas também a "abstinência" das redes sociais ocasiona repercussões negativas segundo os entrevistados, como pode ser observado a partir do excerto retirado da entrevista de Antônio:

A gente fica mais... não sei se ansioso é a palavra certa, né? Mais desesperado porque, tipo, tenta ficar um dia sem WhatsApp, mas não consegue mais, (...) acho que aquela sensação de 'se alguma coisa importante acontecer' você... você fica com aquilo te angustiando.

De maneira mais direta, Antônio usa as palavras angústia e desespero para descrever as sensações e sentimentos que estão associados ao "não ter tempo para acessar" ou "ficar fora das redes". Essa sensação de perda, de não ver ou não participar de "alguma coisa importante" repercute, de acordo com os entrevistados, de forma negativa na subjetividade. Sobre este assunto, alguns participantes explicitaram a mesma percepção, tal como revelou Eduarda: “[...] Então, também é importante dar um tempo na rede social, sabe, ficar um tempo afastado... e aí você volta já com outro relacionamento... você começa a ver de outra forma".
Com efeito, evidenciou-se a conotação de um entretenimento instigante e que ao mesmo tempo é percebido como perigoso porque é capaz de captar a curiosidade dos participantes e convertê-la numa dependência de novidades e assuntos interessantes. Esse sentido subjetivo de dependência condiz com o chamado "medo de perder algo" ou "de ficar de fora" (Fear of Missing Out-FOMO), cuja apreensão diante da possibilidade de perder atividades gratificantes, não fazer parte do que se observa nas redes e o persistente desejo de permanecer conectado são consideradas as características fundamentais (Elhai, Yang, \& Montag, 2020). Diante desta constatação, a percepção das redes como um entretenimento instigante e ao mesmo tempo arriscado resume os sentidos coadunados nessa zona de sentido e abre o caminho para que possamos discutir o que está em jogo nesse ambiente.

(3) Termômetro de Si. A zona de sentido intitulada Termômetro de Si representa a percepção das redes sociais como um meio para desenvolver a percepção de si mesmo e, por conseguinte, a autoavaliação. Esta noção está atrelada, primeiramente, ao fato de que as pessoas tendem a expor aspectos pessoais nas redes, tal como menciona Maria:

Rede social está cada vez mais se tornando um diário, uma coisa que você realmente se expõe, mas na minha opinião não deveria ser, tipo, as pessoas, elas vão se sentindo cada vez mais confortáveis em se mostrar na rede social, mas no futuro isso pode ser gravemente usado contra elas, é uma coisa que eu sinto.

O relato de Maria assinala a modalidade de autoapresentação (self-presentation) que tem sido constantemente analisada por estudiosos das redes sociais (Chua \& Chang, 2016; Fardoulya et al., 2015). Neste contexto, é notório o fato de que o que é exposto tende a ser selecionado pelo usuário do perfil e está sujeito ao crivo dos demais participantes. Consequentemente, a avaliação das postagens traz consigo uma conotação de forma de ser, pensar e atuar do usuário, sob a concepção geral de que expor-se na rede é uma forma de mostrar-se e, portanto, apresentar-se (Rosa \& Santos, 2013).

Nesse aspecto, os entrevistados enfatizaram que é possível tornar-se popular nas redes e essa popularidade é medida pela quantidade de likes obtidos em publicações; ou seja, quanto maior o número de likes, maior a popularidade do usuário. Para os jovens, essa avaliação é feita com base num modelo e isso repercute diretamente na autoestima dos participantes que, na opinião de Eduarda, se comparam constantemente:

Então, tem também esse lado de você começar a botar um modelo na sua vida de como você deveria tá vivendo e isso pode ser muito... pode fazer muito mal pra sua saúde mental. Acho que, principalmente, quando você é mais novo e você não tem consciência disso, porque pelo menos quando vocêjá tem 
consciência disso, você consegue, né? É aliviar um pouco isso. Acho que você pode tá sempre se depreciando e se comparando.

A comparação constante, de acordo com Eduarda, é o foco dessa modalidade de apresentação. Em seu ponto de vista, quando não se tem consciência disso, os efeitos da comparação podem afetar a saúde mental dos usuários. Para Kamila, do mesmo modo, há uma ilusão fomentada pela projeção de personagens que "sempre estão fazendo alguma coisa":

Então, é muito das pessoas que projetam o que elas querem que seja visto, então, por vezes assim é... eu acabei pensando, sei lá, que a vida das pessoas com quem eu me relaciono é muito melhor que a minha, sabe, por existir realmente essa projeção desse... desse personagem assim que a vida de todo mundo é muito boa, então, meus amigos estão sempre fazendo alguma coisa, dá impressão de que eles são muito ativos e, às vezes, eu acabo sobrando por ter ficado em casa no sábado à noite.

Seguindo o caminho trilhado pelas jovens Eduarda e Kamila, o qual foi reiterado inúmeras vezes nos depoimentos dados pelos demais participantes, é possível afirmar que ninguém quer "sobrar" por ter ficado em casa no sábado à noite, no sentido de que a maioria dos jovens não pretende ser diferente dos demais nas redes, porque isso implica certa desaprovação e talvez um possível isolamento. Destarte, numa sorte de efeito manada, a maioria dos jovens tende a adotar esse modelo de interação proposto pelas redes sociais, assim como fizeram quando optaram por aderir às redes.

Portanto, o sentido de comparação constante - foco dessa modalidade de apresentação - passa a ser o "termômetro de si" no tocante à autoavaliação e ao conceito de si mesmo, segundo os entrevistados. Para não ficar em casa "num sábado à noite", num sentido jocoso de expressar um modo diferente de atuar e que pode ser impopular nas redes sociais, os jovens tendem a seguir o padrão de autoapresentação que pode engendrar uma visão positiva para com os demais e, consequentemente, para consigo mesmo. No entanto, para Eduarda, esse padrão ou modelo é ainda mais homogêneo em que pese a diversidade de grupos que interagem nas redes, e redunda em certo culto à perfeição e ao hedonismo:

Então, eu acho que é muito isso, acho é muito um culto à perfeição ao hedonismo. Assim, tipo, sempre. Então, isso pode ser um pouco sufocante, sabe? [...] Acho que o Instagram realmente é 'muito um ambiente', de que muito, tipo, de muita felicidade, muita perfeição e os posts 'tão' sempre reforçando isso, esse hedonismo, essa busca por esse prazer, por essa coisa que, tipo, você nunca vai ter porque não existe isso na vida real. Então, acho que é mais ou menos assim. Mas, se você souber olhar com cuidado, tem muitas coisas que vão servir de inspiração pra você.

Em seu relato, Eduarda mostra como a percepção sobre os demais pode afetar a percepção de si mesmo e a autoavaliação. Os demais entrevistados confirmaram essa concepção de que existe um culto à perfeição e ao hedonismo. Frequentemente, isso aparece em postagens que exaltem felicidade, popularidade, entretenimento e ostentação de poder aquisitivo. Fotos de restaurantes e viagens, por exemplo, são associadas pelos participantes ao estado emocional do usuário, demonstrando uma suposta atmosfera de felicidade sem maiores conturbações, conforme mencionado anteriormente por Kamila.

Diante do exposto, pode-se afirmar que, apesar de criticar o padrão de apresentação gerados pelas redes, tal como exposto no resultado da análise das entrevistas (Exposição da própria vida $=18 \%$, Aparência de vida perfeita ou atmosfera de falsa felicidade $=10 \%$ e Sentimento de competição $=$ $2 \%$ ), a maioria dos jovens entrevistados está ciente das repercussões deste fenômeno social na subjetividade. Eles atribuem a esses modelos e padrões o sentido de um termômetro capaz de "medir a temperatura" da autoestima e do autoconceito dos usuários.

(4) Espelho da sociedade. A última zona de sentido traz uma percepção mais ampla dos participantes: as redes sociais são uma extensão da sociedade à qual eles pertencem, que é capaz de englobar suas dinâmicas, contradições e conflitos. Por isso, optou-se pela nomenclatura "Espelho da Sociedade" para explicitar a noção de que essas redes são compreendidas como um reflexo daquilo que ocorre nas sociedades ao redor do mundo e como um espaço onde são emitidas impressões e opiniões sobre os acontecimentos cotidianos.

Como retratado anteriormente, para esses jovens estar fora das redes é algo concebido como uma forma de isolamento social. Assim, a pessoa que opta por esta escolha é vista por eles como desinformada, alheia aos debates públicos e às informações que circulam rapidamente. Segundo Andrea, há certa pressão para que as pessoas passem a "navegar" nas redes e estejam "dentro disso": "A sociedade meio que vai te empurrando pra essa situação porque, né, se você não tiver dentro disso, você é tipo um E.T., entendeu?". Neste ponto, verifica-se o surgimento discreto da esfera pública em seu relato, quando ela menciona que quem não está dentro é considerado um extraterrestre (E.T). Daí, a ordem do que é público ou privado entra em cena, bem como na perspectiva apontada por Augusto sobre os limites que devem ser respeitados nesse ambiente:

Se você é uma pessoa pública e tal, acho que postar diariamente é normal, duas vezes por dia ainda é normal, mas acho que pra uma pessoa (pausa) normal, pessoa comum, seria o limite assim (pausa) acho que uns três posts por semana, assim acho que é de boa, tranquilo.

Em sua fala, Augusto demonstra que há não apenas uma mescla de assuntos pessoais e coletivos nas redes, senão que "pessoas públicas" gozam de maior aceitação em relação à frequência de postagens diárias. A constatação 
é relevante porque confirma que os jovens entrevistados conseguem discernir a natureza das postagens e as regras implícitas neste ambiente. Ainda mais importante é o fato de eles reconhecerem que existe certa liberdade de expressão e que, às vezes, as pessoas abusam dessa liberdade, conforme relata Clarice: "Eu já vi alguns posts machistas, também, até de amigos meus. Aí, eu vou e comento: 'nada a ver' e não sei o que, ai eu desfaço a amizade com a pessoa porque eu não sou obrigada a ver esse tipo de coisa (risos)."

Ao analisar a opinião dos jovens entrevistados, evidencia-se que o cerne da questão incômoda é o nexo implícito entre assuntos individuais e coletivos. Em outras palavras, eles afirmam que, embora muitos optem por não participar de discussões relacionadas aos assuntos referentes à sociedade, a variedade de postagens, o alcance das mensagens e a rapidez de acesso são fatores que favorecem a participação nesses debates. Por exemplo, Eduarda assinala que a liberdade de expressão é percebida como uma via para denunciar injustiças, realizar boas ações e fomentar algum tipo de engajamento político por parte dos participantes:

As redes sociais também têm um papel importante, talvez de, sei lá, até mesmo de, de digamos assim, de denunciar as injustiças sociais, várias coisas que acontecem, em campanhas... Então, elas facilitam essas boas ações, mas por outro lado, elas também trazem muito isso, de ódio e você começa a ver as coisas.

Não obstante à compreensão deste papel importante das redes sociais na atualidade, esses jovens consideraram que esta via de participação na vida pública pode fomentar diversas condutas negativas que, tal como foram mencionadas por Eduarda, merecem destaque: Agressividade e intolerância (24\%); Invasão de Privacidade (6\%); Falta de ética ou bom senso (6\%). Nesse sentido, a participação nos debates públicos é percebida por eles como algo que pode ocasionar atritos entre os usuários porque, de acordo com Raquel, as redes tornaram-se uma espécie de tribunal, onde as pessoas podem ser discriminadas pelas suas opções políticas e ideológicas:

Você não pode ter uma ideologia diferente do que uma outra pessoa que você já é discriminado por rótulos por todos os lados, 'pedrada'. [...] ]eu vi que aquilo ali realmente era um tribunal que as pessoas viam que podiam falar o que quisessem pra quem quisessem e como quisessem, né?

A conotação de tribunal decorre da percepção de que há liberdade de expressão, mas que a sociedade julga a conduta dos usuários e limita a atuação indisciplinada das pessoas nas redes. De fato, assim como o termômetro que é capaz de influenciar e medir a autoestima e o autoconceito dos participantes, o sentido de espelho da sociedade reflete a tensão da convivência em sociedade que ultrapassa as barreiras do ambiente off-line e alcança o ambiente virtual das redes sociais.

Em meio a essa mistura de postagens pessoais e debates concernentes à sociedade contemporânea, os jovens entrevistados demonstraram ter conhecimento da pluralidade de opiniões e de opções que circulam através das postagens, bem como afirmaram reconhecer que existem informações superficiais $(16 \%)$ e inverídicas. Todavia, é importante advertir que a maioria dos participantes tem consciência de que o tal "reflexo da sociedade" está restrito ao que postam os contatos que o usuário possui dentro do ambiente das redes; portanto, é limitado e não pode compreender a pluralidade de pensamento dentro de uma sociedade, como explica Abigail: "[...] você vive numa bolha, os algoritmos te permitem ver só o que você quer ver, então, você acha que está em uma realidade, mas na verdade, você vive em outra.". O relato supracitado traz à baila que o usuário tem acesso apenas ao que o algoritmo das redes sociais the permite ver. Isto demonstra que essa limitação de assuntos e opiniões pode ser comparada ao conteúdo disponível na tela de uma máquina caça-níqueis que, apesar de girar e variar em relação ao que será exposto, sempre coincide com o conteúdo pré-estabelecido pela máquina. Sendo assim, tal como um espelho que reflete somente o que é projetado, o reflexo produzido pelas redes é restrito, portanto, não é capaz unificar a multiplicidade de elementos que compõem uma sociedade. Entretanto, tal como esclareceram os participantes, as contradições dos seres humanos estão cada vez mais expostas nesse ambiente, o que pode acarretar diferentes níveis de elaboração psíquica (Rosa, Santos \& Chagas-Ferreira, 2016; Rosa et al., 2016). Em síntese, podese concluir que esse sentido subjetivo mais amplo admitido pelos jovens em relação ao ambiente virtual das redes sociais é o de um mundo paralelo que sintetiza, restringe e ao mesmo tempo potencializa o que há de melhor e de pior na humanidade.

\section{DISCUSSÃO}

Os resultados deste trabalho demonstram que os uso das redes sociais repercute na subjetividade dos jovens. Essas redes atraem, modificam condutas e mantém os usuários capturados pelos conteúdos interessantes e gratificações esporádicas oferecidas. Apesar de os aspectos positivos e negativos apontados, esses jovens despendem bastante tempo em vários tipos de redes sociais, sendo Facebook e Instagram as mais utilizadas. A zona de sentido denominada "Capturados pela Rede" expressa o sentido subjetivo da vivência de jovens que seguiram uma modalidade de efeito 
manada ao aderir às redes e logo se sentiram dominados por elas. Neste contexto, de acordo com Carr (2010), quando um meio de comunicação se torna popular, as pessoas ficam fascinadas pela informação - o conteúdo - que ele traz. Assim, elas se interessam pelas notícias nos jornais, pela música na rádio, pelos espetáculos na televisão e pelas palavras ditas por outros através do telefone. Consequentemente, o meio torna-se a mensagem e, como tal, passa a moldar o conteúdo e a relação dos usuários.

No caso das redes sociais, esse meio provê conteúdos variados e interativos, o que poderia gerar ainda mais entusiasmo e adesão. No entanto, a zona de Sentido "Rede Caça-Níqueis" vai além desta constatação ao demonstrar que as gratificações proporcionadas pelas redes geram um sentido de ciclo vicioso que se assemelha às características propostas por Yin et al. (2019) quanto ao "medo de perder algo ou de ficar de fora". Para esses autores, a necessidade de pertença e a inveja são variáveis moderadoras dos efeitos deste medo, de modo que usuários que têm maiores níveis dessa necessidade ou do sentimento de inveja tornam-se mais propensos ao uso compulsivo das redes. Nossos resultados corroboram os achados desses pesquisadores. Nas entrevistas realizadas, percebeu-se que há necessidade de pertença entre os jovens e que, de alguma maneira, concordam que o modelo ou os padrões de interação nas redes fomentam a inveja sob o corolário de "aparência de vida perfeita ou atmosfera de falsa felicidade".

A zona de sentido "Termômetro de si" revela que a comparação constante entre os usuários permeia a autoapresentação (self-presentation) nas redes e impacta diretamente a autoestima e o autoconceito dos jovens. No trabalho realizado por Andreassen, Pallesen e Griffiths (2017), observou-se que a necessidade de "alimentar o ego" e a tentativa de inibir avaliações negativas são os propulsores do uso compulsivo ou aditivo das redes. No caso dos jovens entrevistados, o número de likes é percebido tanto como reforço para a autoestima como um meio para aprimorar o autoconceito. Porém, assim como revelou o estudo de Chua e Chang (2016), o sentido de comparação constante entre pares é visto como algo prejudicial para a autoestima e pode gerar autoapresentações exageradas, com o intuito de favorecer beleza e ocultar feiura, mostrar felicidade e esconder tristeza.

Com efeito, esse "espelho da sociedade" ao qual se referiram os jovens participantes da pesquisa expõe o fato de que a experiência nesses ambientes extrapola a interação, mobiliza sentimentos e emoções, e promove intercâmbios de crenças e valores, ensejando antecipações, ressentimentos, esperanças e dúvidas (Boyd, 2014; Stokols, 2018). Isto posto, conclui-se que essa experiência peculiar repercute de diferentes modos na subjetividade dos participantes, os quais podem ser analisados à luz das características próprias da juventude.

Referenciando a Erikson (1980), poder-se-ia discutir as repercussões das redes sociais na subjetividade tendo como pano de fundo a juventude, enquanto etapa do curso de vida caracterizada pela crise entre a intimidade e o isolamento. Sendo as virtudes preponderantes desse momento a fidelidade e o amor, o imediatismo do viver conectado, a interação e participação constantes no chamado mundo virtual das redes sociais poderiam se constituir em fonte de ansiedade e angústia, modificando os vínculos amorosos dos jovens na atualidade.

Nesta perspectiva, parece que o dilema vivido pelos jovens de hoje vai além da expectativa sobre as tecnologias e tem seu fundamento no que Erich Fromm (2013) apontou como um dos maiores medos da humanidade: o medo da separação (separateness). A angústia de separar-se de seres queridos parece haver sido arrefecida pela agilidade da comunicação nas redes, mas isso não é suficiente para eximir o ser humano de ter que aprender a lidar com esse desafio vital. Portanto, nessa conjuntura, cujo potencial evolutivo inerente à juventude pode ser afetado pela instantaneidade da cultura interativa das redes, pode-se prever que será necessário reaprender não somente a ser jovem, mas, principalmente, a estar sozinho e amar. Eis uma questão importante que merece aprofundamento em estudos futuros.

$\mathrm{Na}$ opinião dos jovens entrevistados, ninguém pretende "ficar em casa num sábado à noite", o que significava permanecer sozinho em decorrência de não ter sido favorecido pelas interações realizadas ou por simplesmente optar por não participar da atividade proposta. Considerando que ficar em casa aludia a não estar presencialmente com outras pessoas, percebe-se que há algo mais paradoxal em jogo: o medo de ficar sozinho, mesmo podendo interagir pelas redes. Nesta direção, os achados deste estudo se tornam ainda mais relevantes em função da situação gerada pela Covid-191 ${ }^{1}$, cujo isolamento imposto foi a medida preventiva adotada em diversos países. À vista disso, esses jovens deixaram de ter a opção de "sair no sábado à noite", o que aumentou vertiginosamente as interações pelas redes sociais. Essas experiências distintas daquelas prévias ao período de pandemia precisam ser investigadas em pesquisas futuras.

Diante do exposto, conclui-se que as redes sociais fazem parte da vida contemporânea e que, tal como apregoou Boyd (2014), introduzem grandes desafios como o de repensar a intimidade, a identidade e as dinâmicas sociais no dia a dia das pessoas. Futuras pesquisas precisam contemplar esses desafios e apontar novos horizontes para que possamos trabalhar com esta realidade que prospera e impacta nos diferentes âmbitos da vida em sociedade. Para tanto, redescobrir a intimidade, repensar a juventude e vislumbrar as transformações do amor talvez sejam os caminhos a serem explorados. Como limitação do presente estudo, podemos apontar o viés da amostra quanto ao nível de escolaridade e outras variáveis que não foram analisadas, tais como o nível socioeconômico.

1 Covid-19: é o nome da doença causada pelo vírus SARS-CoV-2 e é uma abreviação de Corona VIrus Disease 


\section{REFERÊNCIAS}

American Psychological Association-APA. (2010). Dicionário de psicologia. Artmed.

Andreassen, C. S., Pallesen, S., \& Griffiths, M. D. (2017). The relationship between addictive uses of social media, narcissism, and self-esteem: Findings from a large national survey. Addictive Behaviors, 64, 287-293. https://doi.org/10.1016/j. addbeh.2016.03.006

Bento, M. C. (2016). A utilização do facebook por adolescentes, ansiedade, depressão, estresse e vergonha: que ligação? Dissertação de Mestrado, Instituto Superior Miguel Torga.

Best, P., Manktelow, R., \& Taylor, B. (2014). Online communication, social media and adolescent wellbeing: A systematic narrative review. Children and Youth Services Review, 41, 27-36. https:// doi.org/10.1016/j.childyouth.2014.03.001

Boyd, D. (2014). It's complicated: the social life of networked teens. Yale University Press.

Carr, N. (2010). The shallows: What internet during to our brains. Norton.

Carvalho, V. D., Borges, L. O., \& Rêgo, D. P. (2010). Interacionismo simbólico: origens, pressupostos e contribuições aos estudos em psicologia social. Psicologia, Ciência e Profissão, 30(1), 146-151. https://doi.org/10.1590/S1414-98932010000100011

Chua, T. H., \& Chang, L. (2016). Follow me and like my beautiful selfies: Singapore teenage girls' engagement in selfpresentation and peer comparison on social media. Computers in Human Behavior, 55, 190-197. https://doi.org/10.1016/j. chb.2015.09.011

Colás, P., González T., \& De Pablos, J. (2013). Juventud y redes sociales: motivaciones y usos preferentes Young People and Social Networks: Motivations and Preferred Uses. Comunicar, 40(20) 15-23. http://dx.doi.org/10.3916/C40-2013-02-01

Creswell, J. W. (2014). Research Design: Qualitative, Quantitative and Mixed Methods Approaches (4th ed.). Sage.

Elhai, J, D., Yang, H., \& Montag, C. (2020). Fear of missing out (FOMO): overview, theoretical underpinnings, and literature review on relations with severity of negative affectivity and problematic technology use. Brazilian Journal of Psychiatry, Epub May 11. https://doi.org/10.1590/1516-4446-2020-0870

Erikson, E. H. (1980). Identidad, juventud y crisis. Taurus. (Original publicado em 1968).

Facebook. (2020). Informações da empresa. Retirado de https:// br.newsroom.fb.com/company-info/

Fardoulya, F., Diedrichs, P. C., Vartaniana, L. R, \& Halliwell, E. (2015). Social comparisons on social media: The impact of Facebook on young women's body image concerns and mood. Body Image, 13, 38-45.https://doi.org/10.1016/j. bodyim.2014.12.002
Ferrari, C., \& Moraes, R. C. P. (2017). Facebook, tédio e humor: reflexões sobre jovens do interior de São Paulo. Fafibe OnLine, 10(1), 93-105.

Flick, U. (2014). Introdução à pesquisa qualitativa. 3a. ed. Artmed. Fromm, E. (2013). El arte de amar. Paidós. (Original publicado em 1956)

González-Rey, F. L. (2010). Las categorías de sentido, sentido personal y sentido subjetivo en una perspectiva históricocultural: un camino hacia una nueva definición de subjetividad. Universitas Psychologica., 9,1, 241-253. https://doi. org/10.11144/Javeriana.upsy9-1.cssp

González-Rey, F. L. (2005). Pesquisa qualitativa e subjetividade: os processos de construção da informação. Pioneira Thomson Learning.

González-Rey, F. L. (1997). Epistemología Cualitativa y Subjetividad. Educ.

IBGE/PNAD (2018). Instituto Brasileiro de Geografia e Estatística/ Pesquisa Nacional por Amostra de Domicílio Contínua. Acesso à Internet e à televisão e posse de telefone móvel celular para uso pessoal 2016. Retirado de https://agenciade noticias.ibge. gov.br/media/com_mediaibge/arquivos/c62c9d551093e4b8e 9d9810a6d3bafff.pdf

Lévy, P. (1996). O que é virtual. Editora 34.

Owan, V. J., Ekpe, M. B., \& Eneje, S. (2020). Undergraduates' Utilization of Social Networking Media and Sexual Behaviors in Higher Education: A Case Study. Pedagogical Research, 5(2), 2-8. https://doi.org/10.29333/pr/7940

Reich, S. M., Subrahmanyam, K., \& Espinoza, G. (2012). Friending, IMing, and hanging out face-to-face: overlap in Adolescents' online and offline social networks. Developmental Psychology, 48(2), 356-368. https://doi.org/10.1037/a0026980

Rosa, G. A. M., Santos, B. R., \& Chagas-Ferreira, J. F. (2016). Uma cartografia das repercussões das redes sociais na subjetividade. Psicologia em Estudo, 21(2), 279-289.

https://doi.org/10.4025/psicolestud.v21i2.29657

Rosa, G. A. M., Santos, B. R., Stengel, M., \& Freitas, M. H. (2016) Estetización del self en redes sociales: contradicciones humanas y producción subjetiva contemporánea. Revista de Psicologia, 34 (2), 313-336. https://doi.org/10.18800/psico.201602.004

Rosa, G.A. M., \& Santos, B. R. (2013). Facebook e as nossas identidades virtuais. Thesaurus.

Stokols, D. (2018). Social ecology in the digital age: solving complex problems in a globalized world. Elsevier.

Yin, L., Wang, P., Nie, J., Guo, J., Feng, J. \& Lei, L. (2019). Social networking sites addiction and FoMO: The mediating role of envy and the moderating role of need to belong. Current Psychology. https://doi.org/10.1007/s12144-019-00344-4 